\title{
An Approach to the Development of Tourism Marketing Strategies for a New-born City:A Case Study of BuengKan - the Latest Province of Thailand
}

\author{
Mustafa Obay ${ }^{a}$, Enes Demir ${ }^{\mathrm{b}}$, Cahit Pesen ${ }^{\mathrm{c}}$ \\ a JusanaTechakana \\ ${ }^{a}$ Department of Business Administration, King Mongkut's University of Technology North Bangkok, Thailand \\ E-mail:adrchvr@gmail.com
}

Article History: Received: 10 November 2020; Revised 12 January 2021 Accepted: 27 January 2021; Published online: 5 April 2021

\begin{abstract}
BuengKan is a new province not well known among tourists. Moreover, it is in the Northern part of Thailand, which is not a popular destination compared to the Northern and the Southern parts of the country. However, BuengKan has a high potential to develop tourism industry to generate more revenues for the province because it has a variety of tourism resources to develop various types of tourism, and it also is easily accessible. Thus, there is a need to conduct a research on tourist behaviors and attitudes towards BuengKan. A survey research among a sample of customers at working ages in Bangkok, and it has been found that they know BuengKan, but they do not know what they can do or see when they travel to Bueng Kan. Nonetheless, their perceptual pictures of BuengKan are positive in all aspects. Therefore, there should be a good marketing communication campaign to make them know what they can do and see when they are in BuengKan to motivate them to travel to Bueng Kan. In order to formulate a strategy to develop potential of tourism industry in BuengKan, ideas, advices, and recommendations from all stakeholders involved including public sectors, private sectors, communities, and scholars need to be gathered. This is the genesis of a qualitative research conducted with in-depth interviews with public officers, local politicians, chamber of commerce members, private entrepreneurs in tourism industry, scholars in the fields of tourism, marketing, and marketing communications. Their answers from the in-depth interviews have been analyzed and organized as a foundation to formulate an efficient and effective strategy to develop potential of tourism industry in BuengKan. The researcher has proposed the foresaid strategy.
\end{abstract}

Keywords: Tourism behaviors, Strategy, Potential development, Tourism industry, BuengKan province

\section{Introduction}

On March $22^{\text {nd }}$, 2011, BuengKan was proclaimed the $77^{\text {th }}$ province of Thailand. It is the latest province separated from Nongkai Province for the purpose of better governance and more officering security management [1].BuengKan is a new-born province of Thailand right now. Not many people know BuengKan; therefore, they do not have a desire to visit BuengKan. Moreover, BuengKan is in the Northeastern part of Thailand, which is not a popular tourism destination. Tourism in BuengKan has not yet been developed to the utmost potential; there are no strategies to develop and to promote tourism of BuengKan. Nonetheless, when taking a tourism resource audit of BuengKan, one will see that BuengKan has many tourism resources, which makes it possible to develop various types of tourism in BuengKan. What is needed is an integrated task force to work together coherently with frictionless co-operation. The development and the promotion of tourism in this new-born province must gather inputs from all stakeholders involved. In order to get inputs and recommendation, a research must be conducted, so that the findings will be used to develop and promote tourism in this new-born province.

\section{Research Objectives}

1. To study tourists' perception, attitudes, and behaviors regarding tourism in BuengKan.

2. To get ideas and recommendations from all stakeholders involved in the development and the promotion of tourism in BuengKan.

3. To formulate strategies to develop and to promote tourism of a new-born city, so that it will become a popular tourism destination.

\section{Literature Review}

Tourism is important for economic development.Tourism consists of many businesses, and it can create various jobs in the city. It can create multiple effects that make citizens of the city prosperous and have better standards of living. Tourism and economic development reinforce each other. For tourism to be a major factor of overall long-run economic growth, the government must set priorities regarding where and how to use resources 
for national economic growth. More resources should be allocated to tourism and travel industries prior to other segments. Major economic benefits derived from tourism activities include foreign exchange earnings, employments, and income [2]. Once a city has become a tourism destination, a vast amount of revenue will be generated, tax money will increase, and souvenirs will have higher sales volume. It can be concluded hat tourism can make to development, including foreign currency, income and employment [3]. Many developing countries benefit from increasing expenditure on tourism. It is not generally the case that tourism displaces other viable economic activities; rather, tourism provides a source of foreign exchange earnings for countries with little, ornothing else, to trade internationally. The economically poor can benefit through employment and the development of micro enterprise opportunities [4].

A new-born city should be made a popular tourism destination. In the development of tourism in a destination, the first thing to do is to conduct tourism resource audit to create tourism portfolio of the destination. It has been stated that portfolio analysis is a powerful strategic marketing tool [5].To be a popular destination, a new born city must go through a process of branding. Critical to the creation of a durable destination brand is the identification of the brand's values, the translation of tourism resources into a suitably emotionally appealing personality with appealing contents [6]. While this is difficult to achieve in destination marketing, it is not impossible [7]. It involves the stakeholders crucial to the delivery of the destination brand messages with largely web-driven strategy. In the promotion of destination, story telling is tactical interpretation to make a destination popular; therefore, story telling and dialogue are recommended methods of marketing promotion practice [8].Once the city has become a popular tourism destination, more entrepreneurs will invest in various tourism businesses, more jobs will be created, more tourists will come to visit, and more retired people will move to live in. To make a new-born city a popular tourism destination, there must be a task force consisting of public officers, local politicians, private entrepreneurs, prominent community members, and academicians to form development and promotion strategies of tourism. The development must look into all elements of tourism, and the promotion must include both marketing mixes and integrated marketing communications. Infrastructure must be fully developed, and all facilities must be ready to accommodate a greater number of tourists who will visit the city, once it has become a popular tourism destination. Human resource is a very important marketing mix to attract tourists; they have to learn how to provide impressive experiences by employing progressive, experiential and collaborative approach to tourism pedagogy [9].Destination marketing organizations have to implement innovative and appropriate approaches; and use adequate tools and techniques in order to improve marketing activities effectiveness and efficiency. To promote a destination, it is highly recommended that a strong focus on a strategic marketing approach should be adopted and implemented [10].

A successful development of tourism should be community-based tourism.Community-based tourism (CBT) has often been cited as an alternative to mass tourism and an approach for tourism to become more sustainable. If developed well, CBT can become a poverty alleviation mechanism and a way to access improvements in quality of life, providing empowerment and greater economic benefit to individuals in local communities [11]. Community-based tourism has emerged as responsible tourism, pro-poor tourism, sports tourism and moral impacts of tourism. Involvement of community members is an integral part of the task force. They must be heard; their inputs must be well considered. The most important element is human resource; thus, it is essential that people working in tourism businesses and community members be friendly and willing to be effective brand ambassadors of the city. Training and public campaigns are needed to educate human resources and community members to become good hosts that welcome tourists who come to town. It is believed that satisfied tourists will repeat coming to town, and will refer the city to other tourists. Community-based tourism is an important concept of rural tourism. Rural tourism has been regarded as a means of economic and social development in rural areas [12].CBT with community resident involvement is considered as a result of a local initiative, and it demonstrates longer life expectancy, faster growth, and more positive impacts on the local economy [13]. Community-based tourism has emerged as responsible tourism, pro-poor tourism, sports tourism and moral impacts of tourism [14].

\section{Research Methods}

This research is a mixed research, using both qualitative and quantitative methods. The quantitative method was conducted by distributing a structured questionnaire among 400 working people in Bangkok to study their perception, knowledge, attitudes, and behaviors regarding tourism in BuengKan - a new-born province of Thailand. The questions were: how much they know about BuengKan, how they perceive BuengKan, what they think about visiting BuengKan, whether they have been to BuengKan, and whether they consider visiting BuengKan in the future.

The qualitative method was conducted by in-depth interviewing key informants in various fields relevant to the development and the promotion of tourism; they are public officers responsible for the development and the promotion of tourism in a new-born city, local politicians, private entrepreneurs in tourism businesses, members of the Chamber of Commerce of the city, prominent figures of community members, and academicians in the fields of tourism, marketing, and marketing communications. The topics of interview were: SWOT of BuengKan, 
approached to develop tourism of BuengKan, how to make BuengKan a popular tourism destination, the role of the Government, the role of private entrepreneurs, the role of community members, the development of infrastructure, strategic marketing mixes, marketing communication to promote a new-born city, successful factors, and how to overcome all the hindrances.

\section{Results}

Quantitative research findings:The respondents know BuengKan, but do not have much information about the city. They know how to get to the city, they also know that BuengKan has beautiful natural sceneries, and it is a waterfront of the Maekong River. They have positive attitudes toward BuengKan in many aspects; it is a beautiful city, it is safe to be in the city, and it is close to the People Republic of Laos. However, as far as tourism is concerned, most of them have never been to BuengKan, and they do not have any idea about what they can see or do when they are in the city; therefore, they do not have a desire to visit the city. In their perception, they believe that BuengKan might be a city where they can see natural beauty and they can enjoy learning local culture and participate in some religious ceremonies, as the city is separated from Nongkhai-the city with mysterious legends of Naga. In conclusion, the findings reveal that BuengKan has strong tourism potential because it has many tourism resources and people have positive perception of and attitudes toward the city. A major problem is that people do not know much about the city, as it us a new-born province. There is a need to market the city as a do-not-miss tourism destination.

Qualitative research findings: BuengKan has ample tourism resources that can be developed into various types of tourism, including cultural tourism, natural beauty tourism, religious tourism, adventure tourism, sports tourism, agro tourism, and ecotourism. In order to develop and promote tourism of this new-born city, the following things must be done: (1) tourism resource audit, (2) enhancing, modifying, and supplementing tourism resources according to their conditions, (3) preserving natural beauty of the city, as it is known as the gem of the Northeastern part of Thailand, (4) a task force must be formed, so that all stakeholders involved can work together to develop and promote the city, (5) infrastructure has to be fully developed, (6) accessibility to the city and accommodations must be improved, (6) quality of products and services must be upgraded to the world class standards, (7) develop tourism of BuengKan in accordance with the philosophy of sustainability and principles of community-based tourism, (8) formulate a marketing strategy to position this new-born city according to its particular features, (9) launch an integrated marketing communication according to principles of content marketing to disseminate information about the new-born city both off line and on line, (10) launch a public campaign to educate citizens of the city to be proud of being the citizen of BuengKan, to have comprehensive stories of BuengKan, to become effective brand ambassadors of BuengKan, to be friendly and gregarious hosts to welcome visitors, and organize festive events as major events that will lure tourists to visit the city during the event, and (11) make sure that BuengKan has particularities that will be used as unique selling proposition (USP) to give rationale for tourists to decide to travel to Bueng Kan.

Factors that hinder the development of tourism in this new-born city are: (1) hotels and restaurants are not up to good standards, so they must be improved and upgraded, (2) There is not an airport in BuengKan; therefore, local politicians must move to have an airport built in BuengKan along with other components of infrastructure, (3) many citizens of BuengKan are not proud of being citizens of BuengKan; they still have nostalgic feeling of being citizens of Nongkhai-the city with mysterious legend of Naga and an extravaganza event of mysterious Naga firework shooting above the Maekong River in October, and (4) beautiful forests of BuengKan are in preserved areas where visitors can only go to see beautiful sceneries, but cannot have any recreational activities; thus, they cannot attract a large number of tourist. Laws must be amended to allow people who visit the forests to have some recreational activities, such as having a party or a picnic. There must be a balance between tourism and preservation, and (5) BuengKan must differentiate itself from Nongkhai, by making people know things they can see and do in BuengKan that are different from what they can do in Nongkhai. In this case, integrated marketing communication launched by officers involved and storytelling by citizens of BuengKan will help.

In conclusion, things that a new-born city must do are: (1) using content marketing to create knowledge about the city (2) leveraging all tourism resources to develop various types of tourism, (3) organizing many major festive and sports events to lure people to flock into the city during the events, (4) accentuating the particularities of the city and making them unique selling proposition of the city, (5) fully developing all elements of tourism, (6) looking into all marketing mixes of tourism promotion-going beyond 4 P's of marketing mixes, (7) improving and upgrading products and services to world class standards, (8) training and educating people working in tourism businesses to have service minds and effective interactive skills, (9) preparing community members to be effective brand ambassadors and friendly hosts, and (10) developing tourism by leveraging tourism resources of the city according to the philosophy of sustainability and the principles of community-based tourism. 
Challenges that all stakeholders should be aware of and try to overcome are:

1. Conflicts between public officers and private entrepreneurs. The former tries to adhere to policy of development, which sometimes becomes a hindrance of business development. The latter tries to maximize profit, which sometimes violates the philosophy of sustainability and the principles of community-based tourism.

2. Infrastructure in BuengKan needs a lot of improvement to provide convenience for tourists; this affects both accessibility and amenities of tourism in Bueng Kan. Local politicians should move immediately to pressure the central Government to launch a project of infrastructure development with sufficient budgets to carry out the project.

3. Quality standards of products, hotels, restaurants, and other facilities in this new-born city are under acceptable levels, because the entrepreneurs have not plan to accommodate a large number of tourists in the city. From now on, they must pay attention to raise standards of service among their employees. Intensive training is needed promptly.

4. In order to be assured that services will be up to world-class standards, all entrepreneurs in tourism businesses must pay attention to the development of human resources. They must be trained to have service minds, to have high interactive skills, and to have positive attitudes while serving tourists.

5. At present, there is no integrated task force responsible for tourism development and promotion in Bueng Kan. This is quite essential if a new-born city aims at being a popular tourism destination. A frictionless cooperation is needed to be successful. The task force must consist of all relevant stakeholders, especially prominent figures of community members, so that the development will adhere to the principles of community-based tourism, which will benefit citizens of the city.

6. On the supply side, some citizens of BuengKan do not feel proud of being citizens of BuengKan; they still want to be citizens of Nongkhai-the province from which BuengKan was separated. They think that Nongkhai is famous for its mysterious Naga legends. They see people flock into Nongkhai in October to participate in the festival of mysterious Naga firework shooing above the Maekong River. There is a need to change this situation. There must be a campaign to make them know more about BuengKan, to make them feel proud of being citizens of BuengKan, and to make them ready to be brand ambassadors of Bueng Kan.

7. On the demand side, tourists do not know much about BuengKan; they do not have any idea what to do and what to see when they visit this new-born city. It is obvious that marketing and integrated marketing communication strategies are needed to create awareness, knowledge, and attitudes toward BuengKan, so that they will have desire to visit Bueng Kan. They should have clear ideas what they can do and see when they are in Bueng Kan. They should know certain particularities of BuengKan that give them rationale to visit Bueng Kan.

8. At present, there is no integrated task force working on the development and the promotion of tourism of a new-born city; therefore, there is no movement to ask for budget for tourism development and promotion. There are no definite marketing strategies, and there are no integrated marketing communication strategies to promote BuengKan as a tourism destination. These things must happen promptly, and local politicians must be leaders in this movement.

9. At present, beautiful forests in BuengKan are merely field class rooms for tourists to go into and study biodiversity in the forests, and learn preservation behaviors. They cannot do anything for recreational purposes, because there are laws that inhibit them to do so. In order to attract more tourists to come to enjoy beautiful forests with trees, mountains, and waterfalls, the laws must be amended to allow tourists to have some recreational activities, such as parties and picnics in the areas. The balance between preservation and joys of tourism must be well managed.

10. At present, tourists have no ideas what they should buy as souvenirs when they visit BuengKan, despite the fact that BuengKan has many local products for tourists to buy as souvenirs, including silk, local food products, preserved fruits, and decorative artifacts made of rubber. There are no stories to create values for all of these products. A content marketing strategy is needed to make these products valuable among tourists. BuengKan should become a city where tourist would like to visit for souvenir shopping. One has to realize that shopping is a "must" for tourists when they go to different places. It is important that local products be made famous for tourists, so that they feel like coming to the place of origin. That means the city will become a tourism destination.

11. In developing tourism of this new-born city, community members should be able to preserve their rights in managing all tourism resources in the city. People responsible for the formulation of development, marketing, and communication strategies should listen to their inputs to make them feel that they are integral part of the development. 
12. To become successful in developing tourism in a new-born city, human capital is truly a pivotal part of the development. Professional human resource management is needed to prepare employees in tourism businesses to be ready to welcome more tourists who will come to town after a marketing strategy to promote tourism in the new-born city has been launched.

13. As this new-born city was separated from Nongkhai, people involved in the development of tourism in BuengKan have to make sure that they can project particularities of BuengKan, so that it will be differentiated from Nongkhai. Some particularities are already exists; it's a matter of leveraging them as unique selling propositions to sell BuengKan to tourists. Others may not exist at present, but they can be created, such as festive events, sports events, and religious events that are attractive to draw tourists to come to town during the event.

14. Finally, it is important that the development adhere to the philosophy of sustainable tourism. Wealth distribution should be egalitarian and fair. Local citizens must benefit from the development. Social and cultural ways of life must be preserved. Social orders of the city must be maintained. Quality of environment and natural resources must be preserved.

The key informants in this study all agree that the challenges mentioned above have to be well taken and overcome for tourism in this new-born city to become successful with consents from community members. Though there are a lot of things to do, all stakeholders should not feel intimidated or discouraged, because tourism is an integral part of economic development of a new-born city. With its tourism resources, the city has high potential to be successful in economic development of the city. Tourism will have multiple effects that benefit citizens of various occupations. Wealth will be distributed among local citizens, resulting in higher standards of living among citizens of the city.

\section{Conclusion And Discussion}

The findings from both quantitative and qualitative researches indicate that the new-born city has a very good chance to become a popular tourism destination. People who run a new-born city should have a notion that tourism is a right and quick way to generate revenues for the city; therefore, there must be a task force responsible for developing and promoting tourism of the city. As soon as the city was born, a task force must be formed to develop tourism. They have to do tourism resources, and decide what they need to do with the existing resources. Some of the resources should be enhanced; others might have to be modified and supplemented. Some cultural things and natural beauties are to be preserved. More tourism resources can be newly created, such as different events - festive, sports, or religious. Looking at all the resources available in the city, the task force can decide how to position the city, and what types of tourism can be developed to sell the city to tourists.

As far as culture is concerned, architectures of temples, ways of life, and religious ceremonies are among unique selling point of many new-born cities. Other than leveraging the existing sites and ways of life, people involved in the tourism development of a new-born city should try to organize events that will lure tourists to flock into town during the events. Some of them might be sports events that bring in both participants and spectators. Others can be religious events for those who seek pilgrimage tourism. Yet, there must be annual festive events that are extravaganza to bring more people to town. All the events organized should be considered particularities of the city, which make the city different from other city. With unique selling propositions, the city will be attractive to tourists, and with effective marketing and integrated marketing communications, the city will soon become a popular tourism destination bringing in revenues for the city as well as the citizens of the city

For a new-born city to become a popular tourism destination, aggressive marketing and integrated marketing communication strategies are required, and they have to be launched promptly. It is necessary to make people know the city, have clear ideas what they can see and do when that are in the city. The contents to tell stories of the city must project particularities of the city, and give rationale for tourists to visit the city. Positioning the city with different types of tourism will make the city gain a large customer base. Among popular types of tourism that attract tourists are: cultural tourism, natural beauty tourism, sports tourism, recreational tourism, adventure tourism, and religious tourism. In developing tourism for a new-born city, the task force should look into the possibilities to develop various types of tourism to position the city among different target tourists.

It is important for a new-born city to make sure that tourists perceive it to be different from the city from which it was separated. In the case of BuengKan, the campaign must show tourists that BuengKan offer things other than what they can get from visiting Nongkhai. Tourism resources that are available in BuengKan, but not in Nongkhai have to be accentuated. BuengKan needs to organize events that have not been organized in Nongkhai, to make tourists see the differences between Nongkhai and Bueng Kan.

It is inevitable that there must be some obstacles hindering the development, the task force must try to identify all obstacles, and try to overcome it. In order to overcome all the obstacles, frictionless co-operation among 
stakeholders involved in the task force is a "must" They have to be synergistic, coherent, and harmonious. There should not be conflicts among members of the task force, especially public officers and private entrepreneurs. I order to achieve a community-based tourism, community members must be heard; their consents must be received prior to any decision. To go along with the global trend, the development must try to attain the position of sustainable tourism.

In the promotion of tourism in a new-born city, a content marketing strategy is very important. People responsible for the promotional campaign must know what stories should be told, what approaches should be used to tell the stories efficiently and effectively, and what channels should be used to reach the targets. In the past, only mass media channels were means to disseminate information about a city, and that cost a lot of money. Budgets became constraints of promotional communication. Nowadays, digital channels, especially social media are available, and they cost a lot less than mass media. This makes it possible to run an integrated marketing communication campaigns to promote tourism of a new-born city. Not only do those who are responsible for the promotion communicate with target tourists, but citizens of the city should participate in the process of brand curation. They should use their own social media accounts to tell stories of the city.

When a new city is born, there might be several challenges that people in the development and the promotion of tourism have to be aware of and try to overcome. They are: (1) the feeling that they are still citizens of the old city, and not proud of being citizens of a new city, (2) the city is not ready to accommodate a large number of tourists, restaurants, hotels, amenity services, and other ancillaries need to be develop, improved, and upgraded, (3) infrastructure has not been fully developed, local politicians and members of the Chamber of Commerce have to pressure the Government to launch a project to improve infrastructure of a new-born city with sufficient budgets to complete the project, (4) entrepreneurs and employees working in tourism businesses are not ready to work with a lot number of tourists, there must be educational workshops and training sessions to prepare them to be ready to work with an increasing number of tourists, (4) a new born city might have a problem of accessibility; there might not be railways, airports, or wide and good roads; therefore, it is necessary that members of the task force look into this matter, and correct the situation of accessibility, (5) the citizen of a new-born city lack experiences of being good brand ambassadors and good hosts; therefore, there must be an educational campaign to make them good brand ambassadors and good hosts. They should have comprehensive knowledge about the newborn city. They should be made to feel proud of being citizens of the new city. They should help promote the city both on line and off line, (6) any law that hinders tourism development should be amended; the balance between tourism development and sustainability must be well managed, (7) entrepreneurs in the new city might not be aware of souvenir products that are valuable for tourists, they have not improved the quality of the products, and they have no marketing campaigns to create values of the products, and (8) some entrepreneurs are too much profit-oriented, which can jeopardized an attempt to develop sustainable tourism; this matter has to be solved to make entrepreneurs go beyond the idea of maximizing profits without considering the matter of sustainability.

\section{Recommendation}

In order to leverage tourism as a means to generate revenues for a new-born city, the following measures must be implemented.

1. formulate a task force consisting of all relevant stakeholders to work together with integration and frictionless co-operation to come up with a master plan of tourism development and promotion,

2. make sure that all stakeholders in the task force are working to create synergy of development and promotion by working coherently and harmoniously,

3. adhere to the philosophy of sustainable tourism to go along with the global trend,

4. the tourism in a new-born city must be community based, all decisions made should receive consents for community members who preserve their rights of resource management in the development,

5. make sure that wealth distribution is egalitarian and fair among citizens of the city,

6. make sure that social and cultural ways of life are not destroyed,

7. make sure that the development is environmental friendly; quality of environment is well maintained,

8. identify particularities of the new-born city to position the city and to come up with unique selling proposition for the city

9. do not forget to organize various types of major events as annual events on several occasions to bring more tourists into town during the event periods; try to look into possibilities if event organization,

10. make sure that the citizens of the city are well prepared to be effective brand ambassadors and good hosts; provoke them to help communicate stories of the city both off line and on line, 
11. make sure that principles of destination marketing management are deployed to promote a new-born city as a do-not-miss tourism destination,

12. develop and create values for souvenirs products to attract people to come to buy this souvenirs at the place of origin,

13. believe in the power of communication; launch an integrated marketing communication campaign, and continuously carry on the campaign aggressively for at least a few years to come,

14. develop tourism in a new city by looking into all tourism elements of tourism, namely accessibility, accommodations, attractions, activities, amenities, ancillaries, availabilities, atmosphere, amiability,

15. deploy all marketing mixes beyond 4 P's to make sure that the marketing strategic campaign contains all relevant tactical elements, namely (1) Accessibility-- easy to come to, (2) Accommodations--good hotels and good foods, (3) Attractions-- many things to see and many places to visit, (4) Activities-- many interesting things to do, (5) Amenities--augmented services in the city, (6) Ancillaries-- value added activities, performance, festivals, (7) Availability-- tour packages and souvenirs, (8) Atmosphere--quality of environment, cleanliness, and safety, and (9) Amiability--friendliness of community members.

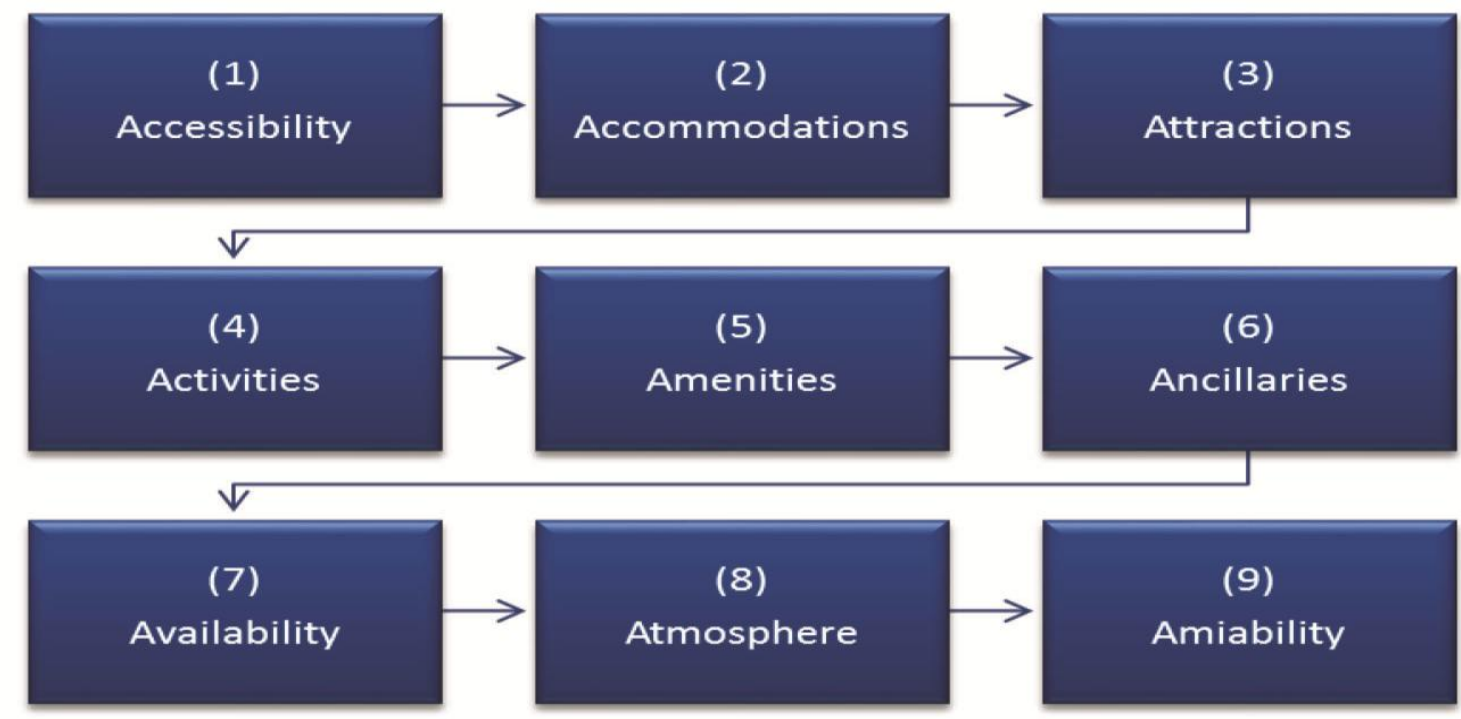

Fig.1 9.A's marketing strategic campaign

16. P's of marketing mixes in promoting tourism in BuengKan are: (1) Product--quality and relevance, (2) Price--reasonable and economical, (3) Place--easy to access, (4) Promotion-- content marketing, (5) Particularity - strong differentiation,(6)Policy--community-based , (7) People--personnel with service mind and interactive skills, (8) Participation--effective involvement of all stakeholders, (9) Program-- items included in tour packages, (10) Preservation-- sustainable tourism, (11) Physical evidence-- beauty, cleanliness, signs, and safety, (12) Process--easy, convenience, fast, and consistent, (13) Population: citizens of the city are good hosts, (14) Partnership:--integrated services among all businesses in tourism industry, (15) Provision:--sufficient budget for development and promotion, (16) Power: political power to launch projects of infrastructure development 


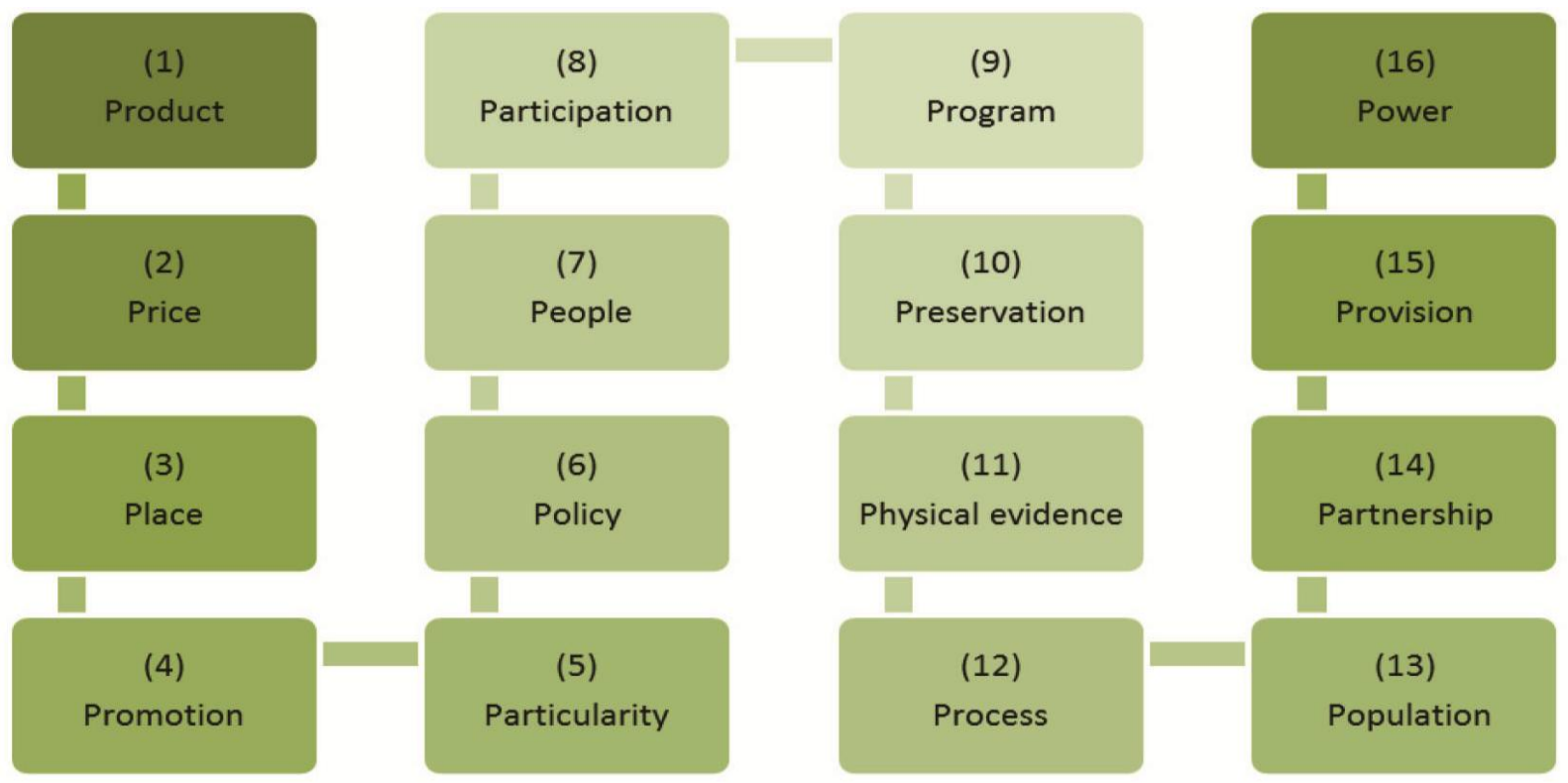

Fig.2 16. P's of marketing mixes in promoting tourism in Bueng Kan

\section{Final Note}

The coalition task force is a key success factor; all stakeholders must be involved. They should provide their inputs, ideas, and recommendations. Prominent figures of community members must participate; whenever they say something, they must be heard. Any decision made must have their consents. This is to make sure that the development gears at being a community-based tourism. The relevant stakeholders who should be parts of the task force are: the Governor of the city, public officers who are responsible for tourism development and promotion, public officers responsible for public relations of the city, members of the Chamber of Commerce, entrepreneurs of hotel business in the city, entrepreneurs of restaurant business in the city, community leaders, local politicians, and local academicians., Not anyone as mentioned above will be missing in the coalition task force, or else, the development and the promotion of the city will not be successful. A new-born city must rely on tourism to generate revenues for the city. Tourism is vital to economic development of the city. Its multiple effects are tremendous, and people who run the city should never underestimate the economic power of tourism

\section{References}

BuengKan was proclaimed the 77 th province of Thailand It is the latest province separated from Nongkoi Provinces for the purpose of better governance and more officering security management", Wikikpedia, On March 22, 2011.

H. Kim, M. Chen, S. Jang, "Tourism expansion and economic development: The case of Taiwan", Tour Manag,Vol. 27, No. 5, pp. 925-933, 2006.

M. Thea Sinclair, "Tourism and economic development: A survey", Journal Development Studies, Vol.34, No.5, pp. 1-51, 2007.

H. Goodwin, "Tourism local economic development and poverty reduction", Applied Research in Economic Development, Vol, 5, No. 3, pp.55-64, 2008.

B. Mckercher, "The Destination-Market Matrix: A Tourism Market Portfolio Analysis Model”, Journal of Travel \& Tourism Marketing, Vol.4, No.2, pp.23-40, 1995.

M. Zapata , C. Hall, P Lindo \& M. Vanderschaeghe, "Can community-based tourism contribute to development and poverty alleviation? Lessons from Nicaragua", Current Issues in Tourism, Vol.14, No.8, pp. 725-749, 2011.

J. Nigel Morgan, A. Pritchard, R. Piggott, "Destination branding and the role of the stakeholders: The case of New Zealand", Journal of Vacation Marketing, Volume: 9 issue: 3, page(s): 285-299, 2003.

I. Simons, "Power and empowerment in community based tourism: Opening Pandora's box?", Tourism Review, Vol. 70, No.1, 72-84, 2015.

T. Jamal, J. Taillon, D. Dredge, "Sustainable tourism pedagogy and academic-community collaboration: A progressive service-learning approach", Tourism and Hospitality Research 11(2):133-147, 2011.

M. Soteriades, "Tourism destination marketing: approaches improving effectiveness and efficiency", Journal of Hospitality and Tourism Technology, Vol.3, No.2, pp. 107-120, 2012.

R. Dodds, A. Ali \& K. Galaski, "Mobilizing knowledge: determining key elements for success and pitfalls in developing community-based tourism”, Current Issues in Tourism, Vol.21, No.13, pp. 1547-1568, 2016. 
A. Farmaki, "An exploration of tourist motivation in rural settings:The case of roodos Cyprus ", Vol.2, No.2-3, 3April-July, pp. 72-78, 2012.

M. J. Zapata , C. Michael Hall , P. Lindo \& M. Vanderschaeghe, "Can community-based tourism contribute to development and poverty alleviation? Lessons from Nicaragua”, Current Issues in Tourism, Volume 14, 2011 - Vol.14, No.8, pp.725-749, 2011.

O. Mtapuri, A. Giampiccoli C. Spershott, "Community-based tourism research in academic journals: A numerical analysis", African Journal for Physical Activity and Health. Vol.21, No.2, pp.688-705, 2015. 